\title{
FLUIDOS PICTÓRICOS: ¿HACIA UNA POÉTICA QUEER?
}

\author{
Rosa Blanca \\ Universidade Feevale
}

\begin{abstract}
Resumen: La indecibilidad de las posibles significancias de imágenes de lo queer genera nuevas estéticas en la contemporaneidad a través de su poetización. El artículo tiene como objetivo investigar esas nuevas formas de subjetivación - plástica - en su concepción escrita. La tensión con que se depara en el momento de la (trans)cripción de la experiencia produce placeres estéticos que, al mismo tiempo, conducen rumbo a la realización de otras obras artísticas. Se sugiere que, en ese proceso creativo, la identidad artística está en sintonía con afectos y deseos sexuales. Se pretende contribuir para el campo de las poéticas visuales, así como para el campo de la literatura, en lo que se refiere a narrativas autobiográficas, poéticas queer y/o feministas. Se propone ampliar las metodologías de la investigación en artes, articulando la práctica artística con la producción textual y donde la autora es la propia artista. Se utilizan las teorías de los afectos, de Patricia Clough (2004) en una perspectiva queer, según Rosa Blanca (2011).
\end{abstract}

Palabras clave: arte contemporáneo; escrita; queer; poéticas visuales; subjetividades.

\section{Introducción}

El presente artículo constituye una poética que anhela visualizar los flujos que se provocan cuando se trata de discernir sobre la (im)posibilidad de expresar un cuerpo sin identidad. El objetivo es investigar procesos de subjetivación en el arte visual, en un contexto cultural mediado por la tecnología electrónica y virtual. ' Se analizan distintas obras de arte utilizando elementos propios de la metodología de la investigación en poéticas visuales, como la documentación fotográfica. Se propone que el trabajo escrito que se realiza en articulación con la práctica artística constituye una forma de producción de conocimiento. La tensión de la experiencia de la creación pictórica genera placeres estéticos que, al mismo tiempo, conducen a la producción de otras imágenes, permitiendo el avance de la investigación. Se prospecta ampliar la metodología de la investigación en artes, a saber, la

Copyright @ 2015 by Revista Estudos Feministas.

' Es presente es parte de la investigación Estudo da Influência das Novas Tecnologias Digitais e Eletrônicas nos Processos e Metodologias de Produção de Obras de Arte na Contemporaneidade (CNPq). 
metodología en poéticas visuales, bajo una perspectiva queer ${ }^{2}$ y de los afectos. ${ }^{3}$ Se pretende contribuir para el campo de las poéticas visuales queer y feministas, así como para el área de la literatura, en lo que se refiere a narrativas autobiográficas y/o poéticas. ${ }^{4}$

Sugiero que existe una sintonía entre una identidad artística y una dimensión gestual y sexual. A partir de ese presupuesto, surge la idea de que el lenguaje corporal de la experiencia poética produce estéticas ambiguas, cuya visualidad puede llegar a transformar el paradigma de las identidades sexuales estables.

Esto no quiere decir que la falta de una política de identidad en el contexto del arte y de la cultura traicione el movimiento feminista y lésbico. Dar cuerpo a los afectos con sus consecuentes desidentificaciones visuales y orgánicas en profunda sintonía con la identidad artística puede llegar a construir y constituir autonomía en sujetos, abriendo otras posibilidades de pensar los relacionamientos, dando fin a la normativa neoliberal heterosexual. En todo caso, hay una correspondencia de sensaciones entre el flujo de los afectos e imágenes de lo trans y de lo queer en ambientes íntimos o digitales que escapan del ritmo económico, y que se configuran en distintas temporalidades en los espacios colectivos y no heteronormativos, cuanto físicos como virtuales. La actualización afectiva de esas imágenes y de esas interacciones intensifica el deseo de la acción artística, con los mismos fines utópicos.

Anhelo transvasar el arte como una expresividad artística que cuestione la colonialidad del poder de lo simbólico y de lo discursivo. ¿Cómo sería una poética de lo queer? Ese es uno de los desafíos. Estoy denominando poética al proceso de creación en el que se produce una reflexión mediante la articulación de una producción plástica con una producción textual.

¿Cómo comunicar la experiencia de un recorrido artístico en una perspectiva queer?

Se define la poética como una experiencia sistémica de potencial transformador del arte. ${ }^{5}$ Considerada como una metodología de la investigación en artes visuales, la poética visual trabaja en el dominio de la intuición, de la singularidad y de la complexidad . Por lo tanto, no puede ser considerada como una metodología semejante al proceso de investigación científico. En esta poética, será privilegiado el nivel de la descripción del proceso artístico por su potencial fenomenológico, que transcribe la trayectoria conforme se presentan las acciones plásticas, sus discernimientos y sus percepciones inmediatas, sin existir algún tipo de juicio de la experiencia o de su intervención con categorías a priori .

Actualmente, existen varias artistas que elaboran una poética visual bajo una perspectiva queer y de los afectos, o bien cuestionando la identidad femenina o masculina. Destaca la poética Corpo Grotesco, ${ }^{6}$ de Talita Gabriela Robles Esquivel. La artista investiga imágenes del cuerpo grotesco a través de formas de mutilación, deformación, exageración y hasta de muerte. Para pensar el cuerpo simbolizado colectivamente, Esquivel usa las teorías de Mijail Bajtin; ${ }^{7}$ para explicar lo grotesco, Esquivel usa la noción de extrañamiento de Wolfang Kayser; ${ }^{8}$ y para posicionar lo grotesco como lo marginal, la artista se vale de Mary Russo. ${ }^{9}$ En esa poética, lo grotesco, si visto como carnavalesco, deforme o mutilado, carece de identidad,

${ }^{2}$ Rosa María BLANCA, 2011.

3 Patricia CLOUGH, 2004.

${ }^{4}$ La primera parte de esta poética fue presentada en el I Fórum: Perspectivas Queer em Debate, organizado por la Profa Dra Eliana Ávila y la Me. Claudia Mayer, Departamento de Lenguas y Literatura Extranjeras, de la Universidad Federal de Santa Catarina (UFSC), Florianópolis, 3 y 4 de septiembre de 2014.

${ }^{5}$ Danielle BOUTET, 2010.

${ }^{6}$ Talita Gabriela Robles ESQUIVEL, 2009.

${ }^{7}$ Mijail BAJTIN, 1987

${ }^{8}$ Wolfang KAYSER, 2003

${ }^{9}$ Mary RUSSO, 2000. 
dado su carácter fenomenológico. En su pintura, la artista aumenta y detalla áreas del cuerpo con la finalidad de traspasar la belleza idealizada tan venerada en la historia del arte occidental. Dado el apuro en la técnica de Esquivel, sus pinturas se revelan atractivas, pero también (extra)ordinarias. En otros momentos, la artista cuestiona la estética de lo femenino, usando como referencia a artistas como Fernanda Magalhães. Para Esquivel, la abyección de los cuerpos fuera del canon está relacionada con la asociación de lo deforme con la muerte o con la degeneración de raza, explica, citando a Umberto Eco. Lo que crea un vínculo entre lo visual y lo racial.

Otra poética importante es la tesis de doctorado de Esmeralda Mancilla Valdez, intitulada Pour un art biocritique: sexualité et action politique, ${ }^{10}$ cuya hipótesis general es mostrar que existe un arte biocrítico compuesto de acciones biocríticas que son la antítesis corporal y sexual, subjetiva y subjetivante, de la sociedad. La artista busca interpretar, bajo la potencialidad crítica del arte biocrítico, acciones artísticas críticas que atraviesan los paradigmas epistemológicos del biopoder falocéntrico patriarcal. Recurre a paradigmas interpretativos como el postestructuralismo, el feminismo y la teoría queer. Para eso, la artista realiza una obra multiorgásmica colectiva, poniendo en evidencia las potencialidades estéticas de los orgasmos autoeróticos en tanto acciones biocríticas individuales que lleva a la constitución de los participantes como sujetos de deseo, en un primer momento, y como sujetos históricos, en un momento posterior. La acción tiene como consecuencia la transformación social, dado el movimiento político y estético. Una de las conclusiones de la poética de Mancilla Valdez es que ese tipo de arte permite luchar contra la sedentarización epistemológica de paradigmas falocéntricos de la cultura hegemónica. Valdez logra realizar una autocrítica estructurada en coherencia con su trabajo artístico, que incluye su propio cuerpo.

En Experiências poéticas sobre as representações da mulher brasileira no imaginário portugués, " Janaína Teles Barbosa construye una poética a través del performance, la fotografía y el vídeo, en el espacio público y en un contexto de migración. El objetivo de Barbosa es indagar si la intervención artística puede levantar cuestionamientos sobre las jerarquías que producen los estereotipos identitarios de la mujer brasileña en Portugal. Mediante prácticas artísticas, la autora produce lo que ella denomina como corpografía, o sea, una desterritorialización del cuerpo femenino y brasileño, para visualizar los imaginarios que interfieren en la vida cotidiana de brasileñas en Portugal, en específico, en la manera en cómo perciben sus identidades. La artista toma como referencia los trabajos de artistas como Irene Salas y Leticia Barreto. Barbosa constata una asociación entre nacionalidad, género y sexualidad. La intensificación de lo sexual en la identidad nacional femenina brasileña en un contexto de mercado sexual, el asedio y la tensión en las relaciones entre Portugal y Brasil, produce capital erótico, sugiere la poética de la artista. Bajo este presupuesto, antiguos estereotipos identitarios colonialistas son revividos por mujeres brasileñas en Portugal, resignificándolos para la elaboración de nuevas identidades. La artista sale a la calle e invita a las personas a marcar sobre la piel de ella un sello que dice "mujer brasileña". Es así como surge el cuerpo desmapeado de la artista, un cuerpo mutante y en constante percepción. Una de las consideraciones finales de la artista es que los métodos artísticos pueden ser utilizados en otras áreas del conocimiento como él designe, la comunicación y las ciencias sociales.

En estas tres poéticas, los presupuestos iniciales surgen desde la intimidad, pero con un fuerte deseo de conectarse con la cultura. El intercambio de significados con distintos campos del conocimiento es lo que genera el avance epistemológico en la poética. Urge que los cursos de artes visuales dialoguen con la cultura a través de la inter y que produzcan

${ }^{10}$ Esmeralda MANCILLA VALDEZ, 2014.

"Janaína Teles BARBOSA, 2011. 
transdisciplinaridad. La problematización de una identidad individual y sexual está en amplias articulaciones con lo político. Lo que tienen en común estas artistas es que provienen de países en descolonización. Es, probablemente, el extrañamiento del territorio cultural nacional - lo que conlleva a un extrañamiento de su identidad y/o hasta de su sexualidad. La necesidad de compartir esa queeridad es lo que produce una poética de lo asombrosamente perturbador, de lo grotesco, de lo sin forma, de lo sin-estético/a.

\section{Hacia una poética}

Como en toda poética, resulta difícil saber el momento preciso en que se da inicio el proceso pictórico - artístico. Intentando encontrar un principio, tomando en cuenta sus objetivos particulares, el proceso artístico puede dar comienzo en el momento en que el /la artista está frente al lienzo y ejecuta la primera pincelada, o bien cuando lanza el primer trazo sobre el espacio en blanco. Para aquellos que creen más en el contexto cultural, el origen de la trayectoria es incierto. En la medida en que la sensibilidad es afectada por elementos de distintos espacios en los que convivimos en la vida diaria, como los oníricos, sociales, antisociales, mediáticos, políticos o existenciales.

Hace parte del presente proceso el trabajo La última visión extraña - queer -, una performance en fotografía que participara en la exposición colectiva Útero, Museu e Domesticidades: Gerações do Feminino (junio - agosto, 2014), en el Museo de Arte de Río Grande do Sul. ${ }^{12}$ En ese trabajo, doy cuerpo a sueños que me asaltan continuamente. Percibo personas que transitan sin alguna identidad posible, las imagino masculinizadas o sin sexo, con una personalidad de identidad múltiple. ${ }^{13}$ Reconozco que es una secuela de mi tesis de doctorado Arte a partir de uma perspectiva queer / Arte desde lo queer.${ }^{14} \mathrm{Esa}$ estética ambigua me seduce (Figura 1):

La visualidad trans de la obra La última visión estraña - queer -, sin lugar a dudas, remite a las pinturas de Romaine Brooks. Para Amparo Serrano de Haro, los óleos de Brooks no tienen el interés de ser objeto de deseo del varón y se centran en las personajes, principalmente en su malditismo, revelando también el ejercicio deliberado de ser "responsable por su propia historia". ${ }^{15}$ Connotan un carácter de libertad por el hecho de haber optado y construido una estética de lo personal y tornarla

Figura 1: La última visión extraña - queer -, con Simone Ávila.

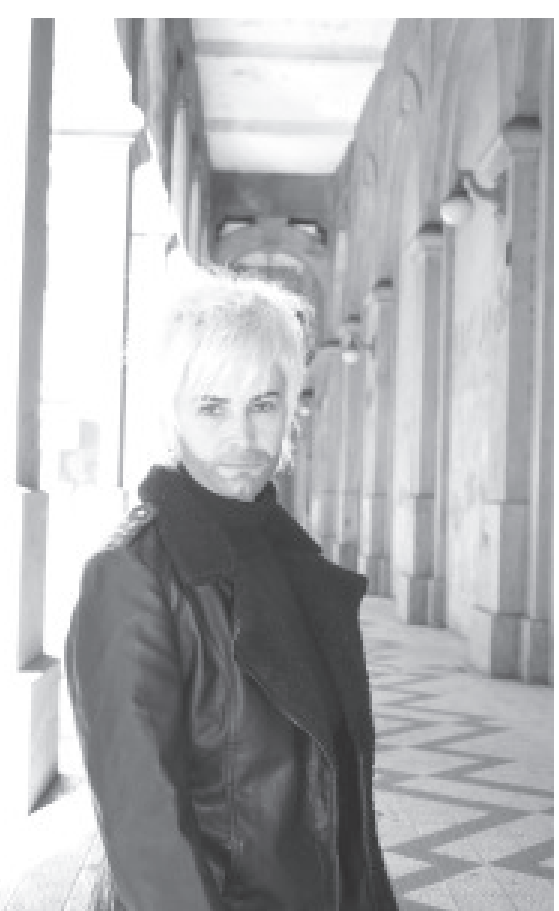

Fonte: Rosa Blanca, 2012.

${ }^{12}$ Ana Zavadil es curadora de la exposición, bajo la dirección de Gaudencio Fidelis.

${ }^{13}$ Rosa María BLANCA, 2013.

${ }^{14}$ BLANCA, 2011

${ }^{15}$ Amparo SERRANO DE HARO, 1994, p. 321. 
pública. La artista se exilió voluntariamente en el período de entre guerras, buscando en París un territorio libre para sus deseos sexuales y proyectos artísticos.

Pero lo que es más relevante es que en el trabajo de Romaine Brooks, así como en el mío (Figura 1), se manifiesta una relación entre la identidad artística y la identidad sexual. Esto puede ser visto por el contexto indicado en la fotografía. Hay un contraste marcado por una iluminación que se refleja excesiva del lado izquierdo y reducida en el lado opuesto. El personaje trans se localiza precisamente en la frontera de ese reflejo. Esa frontera puede ser interpretada como una visión de "sexo intermediario". ${ }^{16}$

En este proceso creativo, no deseo trabajar en la soledad del atelier, para no construir una poética autorreferencial, así que he decidido buscar más que una orientación, una interlocución. De lo único que tengo seguridad es que esa interlocución debe ser realizada con una artista próxima a mi devaneo de lo improbable teórico, de lo improbable identitario, de lo improbable clasificable. ¿A qué estoy denominando queer?

En el momento de presentarse esa posibilidad, de ser D. V. mi interlocutora, me satisfago. D. V. es profesora del Atelier Livre de Porto Alegre. Ella usa silla de ruedas. Que D. V. sea diversa funcional, me traslada a una interfaz queer. Hay una conexión en su diversidad funcional y mi situación dividida entre una sexualidad no-heternonormativa y una condición como extranjera. Ambas vivimos en un contexto neoliberal donde se exigen sujetos productivos, capacitados y heterosexuales. Resistimos en un sistema que tiene como objetivo la (re)producción del binomio normal / anormal, mediante fórmulas cuyo resultado atinge directamente a una dimensión estética, como normalidad $=$ respetabilidad $=$ belleza. ${ }^{17}$ Con la idea de que D. V., como artista, ya ha llegado a percibir más de un extrañamiento en su entorno, en sus sueños y, principalmente, en su manera de interactuar con el arte, de sentir y entender el arte, me hago creer que dialogamos la misma lengua. Parece que tenemos eso y todavía más en común. Compartir esas nuestras experiencias puede significar un "compromiso imaginativo" de una "reconstrucción de saberes subversivos". ${ }^{18}$ ¿Cómo compartir esas experiencias? ¿En qué tipo de espacios?

Muestro a D. V. algunos de los dibujos que vengo efectuando hace más de diez años. Los dibujos muestran sexualidades ambiguas, identidades femeninas, pero al mismo tiempo revocables (Figura 2). Otras presentan más de un sexo:

Figura 2: Serie Afeições (In)quietas

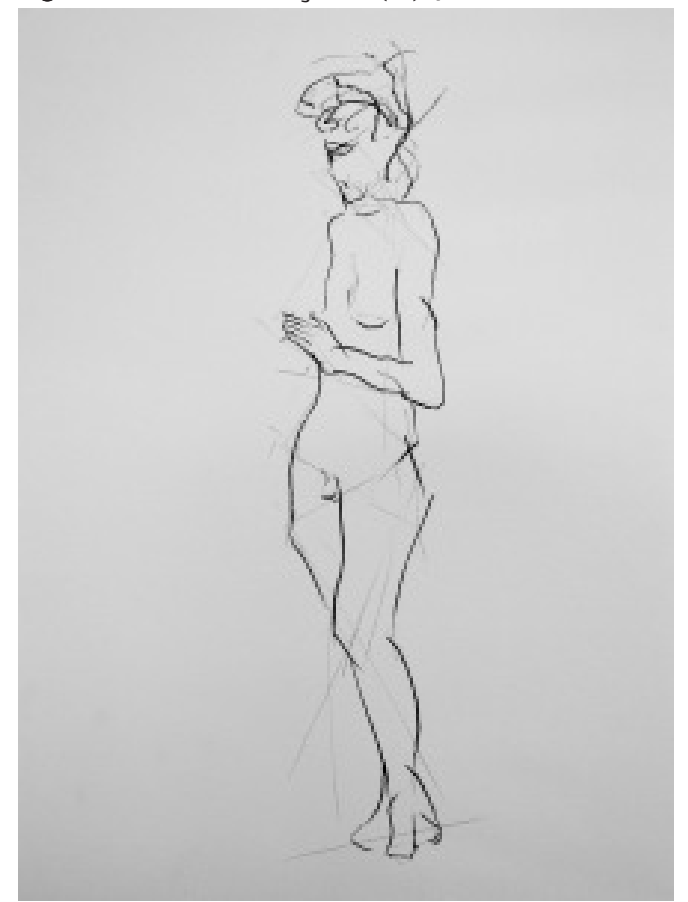

Fonte: Rosa Blanca, 2011.

${ }^{16}$ Tirza True LATIMER, 2005, p. 5.

${ }^{17}$ Paco GUZMÁN y Raquel (Lucas) PLATERO, 2012.

${ }^{18}$ Miriam SOLÁ, 2013, p. 16. 
D. V. Me cuestiona el por qué de mi interés en ese tipo de cuerpos. Le respondo que no tengo más interés. Me parece que lo que he estado dibujando son deseos y afectos de un cuerpo (im)posible, de subjetivaciones irrepresentables, perceptibles solamente en la irresolución del arte. Pero que paradójicamente me produce el deseo de continuar dibujando, pintando y fotografiando.

Ahora me propongo trabajar sin teoría. ¿Podría (des)afirmar las propias teorías y categorías? Por otro lado, tampoco estoy optando por los excesos de la práctica. ¿Cómo expresar un cuerpo sin identidad? ¿Será esa la cuestión actual?

Quiero usar el color. Los clásicos de lo moderno, en el contexto del academicismo, han llegado a afirmar que el color es lo que confiere identidad y distinción a los cuerpos en el espacio pictórico. Me gustaría que la función del color fuese de otro orden. También, me parece obvia la realidad de la abstracción del color. Me encanta el estado pleno del color sin sentido, sin denominativos. Sin embargo, ¿deseo dar cuerpo a lo que no tiene gracia, a lo que carece de exceso o de todos los excesos?

En la nueva etapa de la investigación, el primer ejercicio (Figura 3) consiste en dejarme llevar por mis propias pinceladas, evitando la abstracción, para no orientarme rumbo a mis ideas y teorías. El objetivo es espejarme en mi cuerpo con los trazos arrojados a través de la tinta acuática del acrílico. Las mudanzas en mis afectos son dadas mediante los intervalos entre una pincelada y otra. Sin capas, sólo el arrebato de los juegos de colores, las pinceladas establecen intervalos corporales. Me veo en un cuerpo múltiple, mas también, me miro en todos los cuerpos, ¿o en ningún?:

Figura 3: Autorretrato

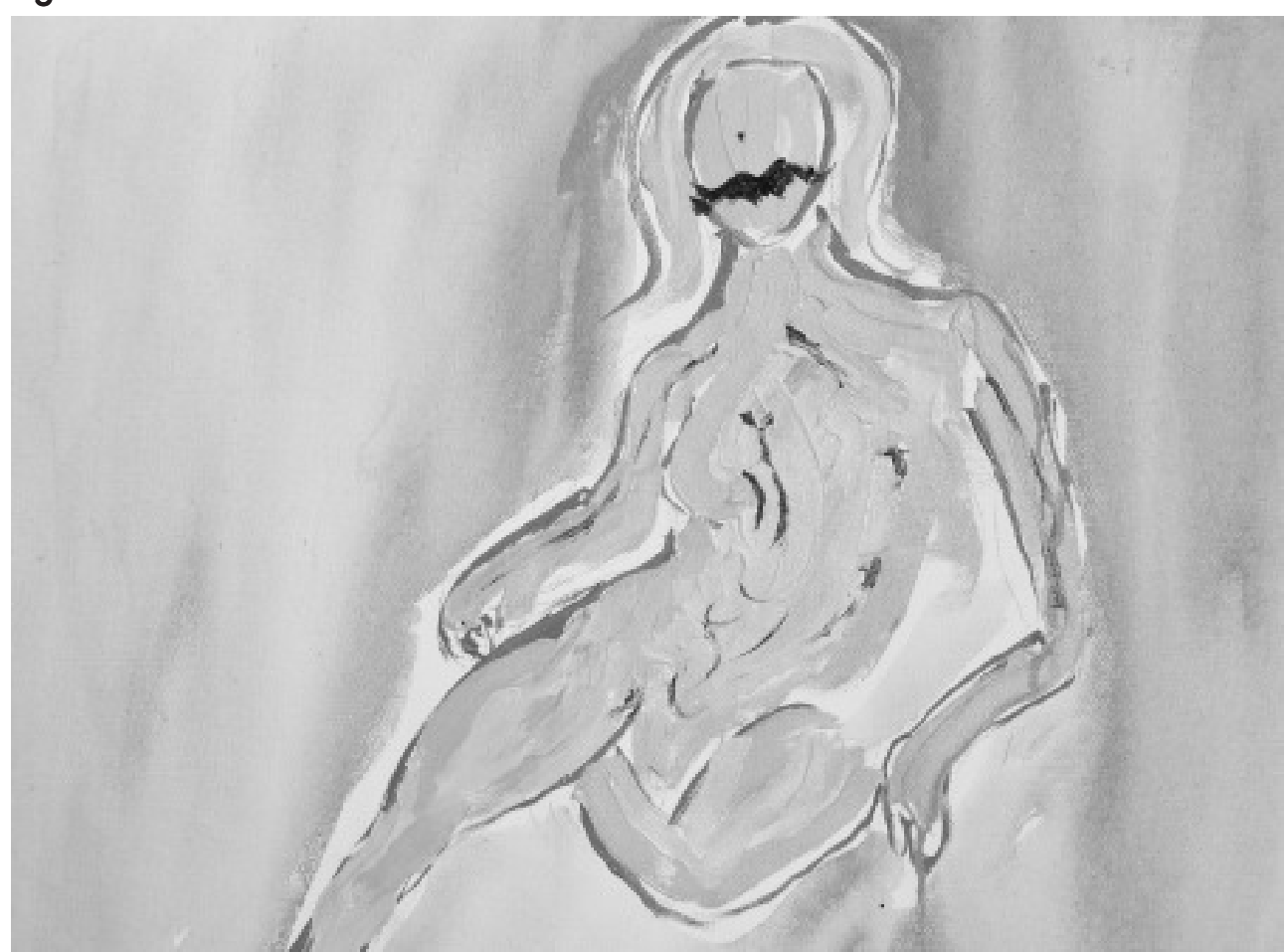

Fonte: Rosa Blanca.

264 Estudos Feministas, Florianópolis, 23(1): 259-267, janeiro-abril/2015 
La inconmensurabilidad de mi cuerpo, que no puedo encontrar cuando gestualizo contra la tela, me lleva a pensar en todas las memorias, experiencias y percepciones que he pasado, que he decodificado, que he hecho parte de mis procesos cognitivos, a través de una identidad no sexual, mas sexuada. ¿De qué otra forma podría ser? Tampoco existen las purezas de los cuerpos. El delito de lo sin forma, poco o nada puede preocuparme. Soy artista. En el arte lo insano es permitido.

La construcción imaginaria de mi cuerpo funda otro cuerpo. Quien sabe y devengo la otra, el otro o las otras. El acto pictórico trastorna las percepciones y, por lo tanto, los códigos de las identificaciones.

Puedo sugerir que el gesto artístico instaura un paradigma de visibilidad, cuya potencia estética no radica en la deconstrucción del género, sino en los afectos que llega a desencadenar. ${ }^{19}$ Hay un cuestionamiento inicial que surge a partir de los márgenes, pero que no claudica. La desidentificación no significa la manufactura de una estética apolítica. La libertad es política. ¿Cómo pintar un cuerpo sin identidad?

En el segundo ejercicio, D. V. me sugiere que me concentre en mis trazos, en mis líneas, sin prestar atención al concepto. "No quiero técnica", afirma. No obstante, debo reconocer que el espíritu que me acompaña - si por acaso existe lo impalpable - durante esta práctica es lo imaginario. Me cuesta percibir lo material, apenas siento lo orgánico. Hay una lucha entre mi trazo y me gesto. Existe un tipo de predestinación gestual, como si el dislocamiento de mi cuerpo previese el límite de mi expiración. Después de la insistencia de mi cuerpo consigo otra extraña experiencia. Siento el flujo de lo sin forma. Todavía más, cuando analizo la imagen en la pantalla de mi note-book. El registro tecnológico y electrónico de mi proceso me parece distante, pero también muy próximo. Existe un desprendimiento corporal que intensifica la plurivalencia de mis afectos. La dificultad en capturar el trazo elementar. La incerteza de la identidad. Todo es imposible.

Investigando, me doy cuenta que la noción insistente de fluir me atinge, ¿lo qué podría ser constituido como perspectiva queer? La idea de flujo me direcciona a considerar a aquellas experiencias artísticas contemporáneas que cuestionan la concepción de cuerpo y sus exudaciones. En específico, estoy refiriéndome a la serie de fotografías intituladas Freischwimmer, del artista alemán Wolfgang Tillmans. Sin embargo, comparando con mis experiencias, las imágenes de Tillmans realizadas bajo el efecto de la luz evocan fluidos orgánicos. Freischwimmer está vinculado directamente con la vida privada de Tillmans, interceptada por la epidemia del SIDA. ${ }^{20}$ La imagen de fluido afectaría a toda una comunidad queer en los años ochenta, por las metáforas relacionadas con los deseos corporales que implicaría. Las fotografías de Tillmans resisten a ser constituidas como imágenes del hedonismo absoluto de una globalización saludable, limpia y pura. Tillmans no está interesado en las cultivadas características específicas del medio, reivindicadas por un arte reducido a sus especializaciones, academismos institucionales y dominios técnicos.

\section{Consideraciones finales}

Los extrañamientos en la trayectoria de un arte que se debruza sobre modelos de ser, actuar y pensar dominantes parecen acentuar la (in)certidumbre de una percepción (in)confiable. El intercambio y puesta en común de esas experiencias artísticas, en la academia y hasta en la propia ciencia, puede llegar a transformar las formas en que se trabaja una metodología, principalmente cuando lo que está en juego es la manera como están siendo conceptualizados los procesos de subjetivación.

${ }^{19}$ Frédérique VILLEMUR, 2007.

${ }^{20}$ Damien DELILLE, 2000. 
La presente poética está en el inicio de un recorrido que, probablemente, nunca será concluido. Se constituye como un trabajo en proceso, a work in process. Pero, por otro lado, no puedo dejar de percibir, a través de las complicaciones de estas poéticas de lo queer, que mi trabajo permite la experiencia de fluido como espontaneidad, como imprevisible.

La subjetivación artística encuentra su eclipse frente al cuestionamiento de lo sexual y lo identitario. Es un hecho que la cientificidad está presente. Eso puede llegar a condicionar el proceso metodológico de pintar y dibujar, repercutiendo en la manera como se presenta el cuerpo, mi cuerpo. Pensar lo contrario, invocar una idea de transcendencia, sería el prenuncio de un idealismo que no existe. Los cuerpos no son finitos, pero tampoco no son infinitos. Esa documentación visual del proceso de invención del cuerpo debe ser revista. Las visualidades que resultan del proceso pictórico en una poética documentada fotográficamente, como la presente, pueden alejarse del proceso de la experiencia. Sin embargo, es con la escrita que la obra enuncia el cuerpo latente.

La pregunta que continúa norteando este tipo de poéticas vuelve a ser la misma: ¿Es posible expresar un cuerpo sin identidad?

\section{Referencias}

ARGAN, Giulio Carlo. Arte moderna. São Paulo: Companhia das Letras, 1992.

BAJTIN, Mijail. La cultura popular en la Edad Media y en el Renacimiento. Madrid: Alianza Editorial, 1987.

BARBOSA, Janaina Teles. Corpo des-mapeado: experiências poéticas sobre as representações da mulher brasileira no imaginário português. 2011. 118 p. Dissertação (Mestrado em Design da Imagem)-Faculdade de Belas Artes, Universidade do Porto, Porto, 2011.

BLANCA, Rosa María. Arte a partir de uma perspectiva queer/arte desde lo queer. 2011 . 396 p. Tese (Doutorado em Ciências Humanas)-Programa de Pós-Graduação Interdisciplinar em Ciências Humanas, Universidade Federal de Santa Catarina, Florianópolis, 2011. . La última visión extraña - queer-, con Simone Ávila (2012). Fotografia.

. "Sonhos queer - afetos fotográficos". In: BLANCA, Rosa Maria (Org.). Poéticas abertas. Novo Hamburgo: Feevale, 2013.

"Transponiendo la estética al espacio ambiental". Prâksis, Novo Hamburgo, ano 4, V. 1, p. 31-35, jan. 2007.

BOUTET, Danielle. II - L'expérience artistique: réfléchir, comuniquer. Récits d' artistes. [S.I.], [2010]. Disponível em: <http://www.recitsdartistes.org/documents/textes-theoriques/0/2_2reflechir-communiquer.pdf > . Acesso em: 14 jul. 2014.

CLOUGH, Patricia Ticineto. "Future matters: technoscience, global politics, and cultural criticism". Social Text 80, Durham: Duke University Press, v. 33, n. 3, p. 1-23, 2004.

DELILLE, Damien. Fluides abstraits: Wolfang Tillmans et la recomposition du militantisme au tournant des années. Paris: Université Paris 1, 2000. Disponível em: <http://hicsa.univparis 1.fr/documents/pdf/PublicationsLigne>. Acesso em: 10 jul. 2014.

ESQUIVEL, Talita Gabriela Robles. Corpo grotesco. 2009. 107 p. Dissertação (Mestrado em Artes Visuais) - Programa de Pós-Graduação em Artes Visuais, Universidade do Estado de Santa Catarina, Florianópolis, 2009.

GUZMÁN, Paco; PLATERO, Raquel (Lucas). "Passing, enmascaramiento y estrategias identitarias: diversidades funcionales y sexualidades no-normativas". In: PLATERO, Raquel (Lucas). Intersecciones: cuerpos y sexualidades en la encrucijada. Barcelona: Bellaterra, 2012.

HALBERSTAM, Judith. In a queer time \& place: transgender bodies, subcultural lives. New York: New York University Press, 2005. 
KAYSER, Wolfang. O grotesco: configuração na pintura e na literatura. São Paulo: Perspectiva, 2003.

LATIMER, Tirza True. "Visions émancipatrices. Portrairute et identité sexuelle dans le Paris des annés 20". Clio, Histoire, Femmes et Societés, Saint-Denis La Plaine, n. 22, p. 1-3, 2005.

MANCILLA VALDEZ, Esmeralda. Pour un art biocritique: sexualité et action politique. 2014. 973 p. Tese (Doutorado em Artes e Ciências da Artes). École Doctorale d'Arts Plastiques, Esthétique et Sciences de l'Art (APESA), Université Paris 1 - Panthéon - Sorbonne, Paris, 2014.

RUSSO, Mary. O grotesco feminino. Rio de Janeiro: Rocco, 2000.

SOLÁ, Miriam. "Introducción: pre-textos, con-textos y textos". In: MIRIAM, Solá; URKO, Elena. Transfeminismos: epistemes, fricciones y flujos. Tafalla Nafarroa: Txalaparta, 2013.

VILLEMUR, Frédérique. "Pensée queer et mélancolie du genre". Cahiers du Genre, l'Harmattan, v. 2, n. 43, p. 153-169, 2007.

[Recebido em outubro de 2014

e aceito para publicação em novembro de 2014]

\section{Pictorial Fluids: Towards a Queer Poetics?}

Abstract: The non-speakability of the possible meanings of images such as the queer generates new esthetics in the contemporaneity through its transformation into poetics. The article investigates those new forms of - plastic - subjectivation in its written conception. The tension it faces at the moment of the (trans)cription of the experience produces esthetical pleasures that, at the same time, lead to the accomplishment of other artistic works. We suggest that, in this creative process, the artistic identity is tuned with affections and sexual desire. This work aims at contributing for the field of the visual poetics, as well as for the literature, regarding autobiographic narratives, queer and/or feminist poetics. We want to broaden the methodologies to investigate the arts, articulating the artistic practice with the textual production, where the writer is the artist her/himself. The work is based on the theories of the affections, by Patricia Clough (2004) and a queer perspective, according to Rosa Blanca (2011).

Key Words: Contemporary art; Writing; Queer; Visual poetics; Subjectivities 